\title{
Cerium-Free Luche Reduction Directed by Rehydrated Alumina
}

Ebenezer Jones-Mensah, ${ }^{\dagger}$ Leslie A. Nickerson, ${ }^{\dagger}$ Jackson L. Deobald, Hailey J. Knox, Alyssa B. Ertel, Jakob Magolan*

Department of Chemistry, University of Idaho, Moscow, ID 83844-2343

\begin{abstract}
A 1,2-regioselective reduction of $\alpha, \beta$-unsaturated ketones to their corresponding allylic alcohols is accomplished with $\mathrm{NaBH}_{4}$ in the presence of acidic activated alumina rehydrated to the Brockmann II grade by adding 3\% w/w water. The substrate scope includes eight ketones reduced in high regio- and diastereoselectivity to their corresponding allylic alcohols. This is the first example of the strategy of systematically tuning the surface chemistry of alumina via partial rehydration in order to modulate selectivity in a reaction. Alumina is an appealing alternative to the common Luche reduction additive, $\mathrm{CeCl}_{3}$, from the perspective of cost and procedural simplicity.
\end{abstract}

\section{Key Words:}

Alumina, Brockmann, Hydration, Selective Reduction, Unsaturated Ketones, Sodium Borohydride

\section{Graphical Abstract:}

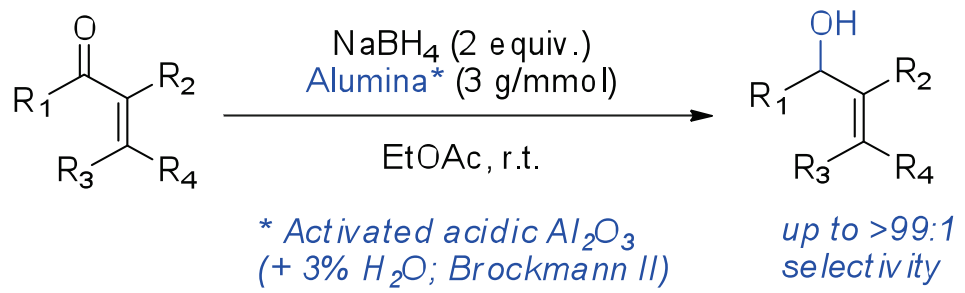




\section{Introduction}

Transition aluminas $\left(\gamma-, \delta-, \kappa-, \chi-\right.$, and $\left.\eta-\mathrm{Al}_{2} \mathrm{O}_{3}\right)$, often broadly termed 'activated' aluminas, are the products of thermal dehydration of various polymorphs of aluminum hydroxide $\mathrm{Al}(\mathrm{OH})_{3}$. ${ }^{1,2}$ The structural and surface characteristics of transition aluminas have been extensively studied. ${ }^{3-6}$ With high-surface areas, Lewis acidic, Brønsted acidic, and basic surface sites, activated aluminas have found use as catalysts and catalyst supports for both industrial processes ${ }^{1}$ and laboratory-scale organic chemistry. ${ }^{7-13}$

In 1941 Brockmann and Schodder altered the chromatographic behavior of activated alumina by adding water and equilibrating in a closed vessel at room temperature. ${ }^{14}$ The resulting 'Brockmann Scale' (numbered I-V and corresponding to approximately 0, 3, 6, 10, and $15 \%$ $\mathrm{w} / \mathrm{w}$ water added to activated alumina) now serves as general terminology used to crudely quantify and standardize the degree of dehydration/rehydration (or activation/deactivation) of some activated aluminas. ${ }^{15}$ Activated aluminas are typically sold at the Brockmann I grade which corresponds to a water content of 1-1.5\% as determined by Karl Fisher titration (or $\mathrm{Al}_{2} \mathrm{O}_{3} \cdot n \mathrm{H}_{2} \mathrm{O}$ where $\left.n=0.06-0.08\right) .{ }^{15}$

The apparent simplicity of Brockmann's hydration scale is starkly contrasted by the complex and multi-faceted relationships that exists between degree of hydration and the surface properties, particularly Lewis acidity, of aluminas which continue to be elucidated. ${ }^{16}$ While a number of chemo-, regio-, and stereoselective reactions at alumina surfaces have been reported, ${ }^{17-21}$ the degree of hydration of aluminas has not been generally considered as a variable with a potential impact on reaction selectivity.

Schuchardt and co-workers have published a series of reports describing the use of aqueous $\mathrm{H}_{2} \mathrm{O}_{2}$ in the presence of alumina to epoxidize olefins. ${ }^{22-25}$ The authors investigated the role of water in the context of catalytic activity of alumina surfaces. They correlated the amount of water per unit of surface area of alumina to the hydrophilicity of the alumina surfaces and concluded that the epoxidations proceeded best with an optimal level of hydrophilicity that was high enough to promote rapid interaction of the alumina surface with hydrogen peroxide but also low enough to avoid impeding the approach of olefin substrates to the active sites. ${ }^{23}$

The concept of "wet alumina" (water added to commercially available alumina), has appeared several times in synthetic literature primarily in the context oxidations of a variety of substrates using chromium (VI) oxide, ${ }^{26-28}$ potassium peroxymonosulfate $\left(\right.$ Oxone $\left.{ }^{\circledR}\right),{ }^{29-32}$ and other oxidants, ${ }^{33,34}$ supported on wet alumina. As part of our broader efforts to develop heterogeneous tools that reduce the environmental footprint, cost, and procedural complexity of synthesis, ${ }^{35,36}$ we recently began looking closer at the rehydration of activated aluminas as practical strategy for modulating reactivity and selectivity.

Wet alumina was first used to effect a synthetic transformation by Morinoto and co-workers in $1991 .^{32}$ The authors described a Baeyer-Villiger Oxidation of several ketones in the presence of Oxone and wet alumina in dichloromethane. The alumina was prepared by adding $20 \% \mathrm{w} / \mathrm{w}$ water to a commercial alumina followed by vigorous shaking. The word 'wet' did not imply the presence of a slurry as the alumina remains a free-flowing powder after addition of water. As 
the authors did not report whether studies were conducted that led them to choose $20 \%$ as a suitable amount of water, we decided to conduct a brief experiment of our own to investigate this issue. The results of our study are illustrated in Figure 1. We used commercially available acidic, activated alumina, Brockmann I grade, with water added in eight sequential increments from 0 to $28 \% \mathrm{w} / \mathrm{w}$. These rehydrated aluminas were combined with Oxone, and 4-tertbutylcyclohexanone in ethyl acetate and the mixtures stirred for eight hours at room temperature followed by filtration and analysis of the crude reaction mixtures by ${ }^{1} \mathrm{H} N \mathrm{NM}$. We found the yield of the Baeyer-Villiger Oxidation product, $\gamma$-tert-butyl- $\varepsilon$-caprolactone, to be dependent on the amount of water that been added to the alumina. The maximum NMR yield of $68 \%$ was observed with $16 \% \mathrm{w} / \mathrm{w}$ water. At $8 \%$ water and below, we observed less than $5 \%$ of the lactone.
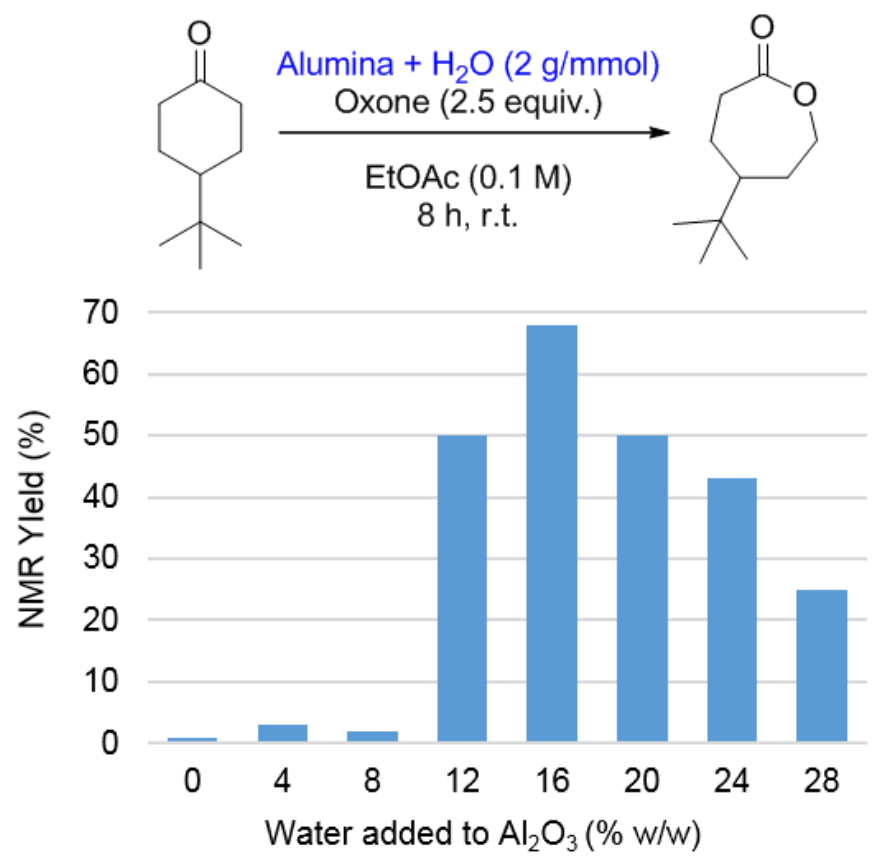

Figure 1. Effect of water content of alumina on the yield of the Bayer-Villiger Oxidation of 4tert-butylcyclohexanone with Oxone and wet alumina. (Product yields were determined via ${ }^{1} \mathrm{H}$ NMR with anisole used as an internal standard.)

We considered the above result to be a clear demonstration that the degree of rehydration of alumina is a significant and potentially valuable variable in the context of new reaction development whenever alumina is a support or catalyst. Consequently, we have begun an effort to investigate new potential applications of rehydrated aluminas. As our first original contribution in this area, herein we describe a simple and inexpensive process that employs partially rehydrated activated acidic alumina $(3 \% \mathrm{w} / \mathrm{w}$ water added; Brockmann II) to promote the regioselective 1,2-reduction of $\alpha, \beta$-unsaturated ketones with sodium borohydride $\left(\mathrm{NaBH}_{4}\right)$ in ethyl acetate (EtOAc). 


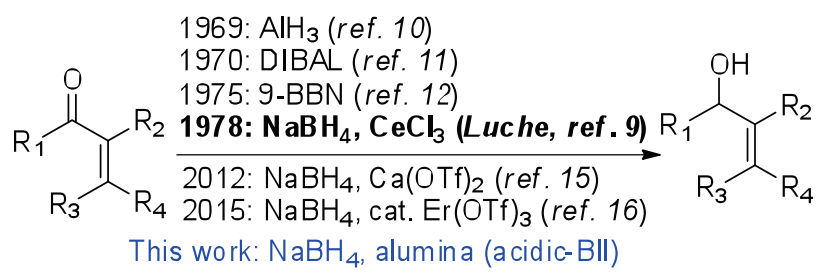

Scheme 1. History of 1,2-Reductions of $\alpha, \beta$-Unsaturated Ketones.

The Luche reduction of $\alpha, \beta$-unsaturated ketones to allylic alcohols with $\mathrm{NaBH}_{4}$ in the presence of stoichiometric $\mathrm{CeCl}_{3}$ in methanol was reported in 1978 (Scheme 1). ${ }^{37,38}$ This mild protocol was preferable to previous approaches with $\mathrm{AlH}_{3},{ }^{39} \mathrm{DIBAL},{ }^{40}$ or $9-\mathrm{BBN},{ }^{41,42}$ and has remained the primary method of choice for more than thirty-five years with few others reported. ${ }^{43}$ In 2012, Fuchter and co-workers, seeking alternatives to lanthanides and expanding upon work by Utimoto, ${ }^{44}$ found that $\mathrm{Ca}(\mathrm{OTf})_{2}$ was a suitable substitute for $\mathrm{CeCl}_{3}{ }^{45}$ In 2015 , Nardi used catalytic $\operatorname{Er}(\mathrm{OTf})_{3}$ to achieve selective reductions in 2-MeTHF (Scheme 1). ${ }^{46}$

Gemal and Luche attributed the 1,2-selectivity of their $\mathrm{NaBH}_{4} / \mathrm{CeCl}_{3} / \mathrm{MeOH}$ system to two factors: 1) Brønsted acid coordination of $\mathrm{MeOH}$ (enhanced by $\mathrm{CeCl}_{3}$ ) to the enone, and 2) the conversion of $\mathrm{NaBH}_{4}$ to $\mathrm{NaB}(\mathrm{OMe})_{\mathrm{n}} \mathrm{H}_{4-\mathrm{n}}$ species more selective for 1,2-hydride delivery. ${ }^{38}$ Nardi's recent protocol used an aprotic solvent (2-MeTHF) which could neither react with $\mathrm{NaBH}_{4}$ nor engage in Brønsted-type coordination to the substrate, leaving Lewis Acid coordination by $\operatorname{Er}(\mathrm{OTf})_{3}$ to the enone as the sole rationale for selectivity ${ }^{46}$ One might consider $\mathrm{Er}(\mathrm{OTf})_{3}$ to be ideally suited to predispose $\alpha, \beta$-enones toward reaction with $\mathrm{NaBH}_{4}$ in a 1,2fashion. With these studies in mind we decided to investigate the strategy of 'tuning' alumina acidity via rehydration in the context of $\mathrm{NaBH}_{4}$-mediated reduction of enones. Relative to all of the previous strategies described above, we considered the use of $\mathrm{NaBH}_{4}$ paired with alumina to be preferable in terms of cost, procedural simplicity, and environmental impact.

\section{Results and discussion}

We began by treating 2-cyclohexenone (1) with $\mathrm{NaBH}_{4}$ in the presence of a series of aluminas (Table 1). A control reaction with $\mathrm{NaBH}_{4}$ in methanol in the absence of an additive resulted in a 1:1 mixture of alcohols $\mathbf{2}$ and $\mathbf{3}$ (entry 1 ) while Luche conditions gave exclusively the allylic alcohol (2, entry 2). Treatment of $\mathbf{1}$ with $\mathrm{NaBH}_{4}$ (1 equiv.) in the presence of activated neutral alumina Brockmann Grade $\mathrm{I}\left(\mathrm{Al}_{2} \mathrm{O}_{3}\right.$-neutral-B1, $\left.1 \mathrm{~g} / \mathrm{mmol}\right)$ in $\mathrm{MeOH}$ yielded primarily the dimethylacetal of $\mathbf{1}$ (entry 3 ) in accordance with previous reports of alumina-mediated carbonyl acetylations. ${ }^{47,48}$ When a series of non-alcoholic solvents were evaluated, most were found to yield an unfavorable ratio of 2 to 3 . Ethyl acetate, which offered a 54:46 ratio in favor of the allylic alcohol 2, was selected as a suitable solvent for further optimization of the alumina additive (entry 4).

Table 1. Optimization of Alumina Additive for the Reduction of 2-Cyclohexenone. ${ }^{a}$ 


\begin{tabular}{|c|c|c|c|}
\hline & $\begin{array}{l}\mathrm{NaBH}_{4} \text { (1 e quiv) } \\
\text { additive }\end{array}$ & & \\
\hline 1 & $\begin{array}{l}\text { solvent } \\
\text { rt, } 24 \mathrm{~h}\end{array}$ & 2 & \\
\hline Entry & Additive & Solvent & $2: 3^{b}$ \\
\hline 1 & None & $\mathrm{MeOH}$ & $50: 50$ \\
\hline 2 & $\mathrm{CeCl}_{3}{ }^{\mathrm{c}}$ & $\mathrm{MeOH}$ & $>20: 1$ \\
\hline 3 & $\mathrm{Al}_{2} \mathrm{O}_{3}$-neutral-B1 ${ }^{\mathrm{d}}$ & $\mathrm{MeOH}$ & $\mathrm{n} / \mathrm{a}^{\mathrm{e}}$ \\
\hline 4 & $\mathrm{Al}_{2} \mathrm{O}_{3}$-neutral-B1 & EtOAc & $54: 46$ \\
\hline 5 & $\mathrm{Al}_{2} \mathrm{O}_{3}$-neutral-B2 & EtOAc & $75: 25$ \\
\hline 6 & $\mathrm{Al}_{2} \mathrm{O}_{3}$-neutral-B3 & EtOAc & $68: 32$ \\
\hline 7 & $\mathrm{Al}_{2} \mathrm{O}_{3}$-neutral-B4 & EtOAc & $65: 35$ \\
\hline 8 & $\mathrm{Al}_{2} \mathrm{O}_{3}$-basic-B1 & EtOAc & $46: 54$ \\
\hline 9 & $\mathrm{Al}_{2} \mathrm{O}_{3}$-basic-B2 & EtOAc & $70: 30$ \\
\hline 10 & $\mathrm{Al}_{2} \mathrm{O}_{3}$-basic-B3 & EtOAc & $69: 31$ \\
\hline 11 & $\mathrm{Al}_{2} \mathrm{O}_{3}$-acidic-B1 & EtOAc & $57: 43$ \\
\hline 12 & $\mathrm{Al}_{2} \mathrm{O}_{3}$-acidic-B2 & EtOAc & $79: 21$ \\
\hline 13 & $\mathrm{Al}_{2} \mathrm{O}_{3}$-acidic-B3 & EtOAc & $71: 29$ \\
\hline \multicolumn{4}{|c|}{$\begin{array}{l}\text { a. } \text { Reaction conditions for entries 3-13: } 2 \text { - } \\
\text { cyclohexenone ( } 1 \mathrm{mmol}), \mathrm{NaBH}_{4}(1 \mathrm{mmol}) \text {, } \\
\text { alumina }(1 \mathrm{~g}) \text {, solvent }(5 \mathrm{~mL}), \mathrm{rt}, 24 \mathrm{~h} .{ }^{\text {b. }} \text { Ratio } \\
\text { determined using }{ }^{1} \mathrm{H} \text { NMR after filtration. } \\
\left.{ }^{\text {c. }} \text { Luche conditions were employed (see ref. } 38\right) \text {. } \\
{ }^{\text {d. }} \text { Neutral, basic, and acidic Brockmann I } \\
\text { activated aluminas (Aldrich) were used as } \\
\text { purchased (B1) or pre-modified by addition of } \\
\text { water (B2-B4, see Experimental section). }{ }^{\text {e. }} \text { The } \\
\text { dimethyl acetal of } 1 \text { was the major reaction } \\
\text { product. }\end{array}$} \\
\hline
\end{tabular}

Brockmann II neutral activated alumina $\left(\mathrm{Al}_{2} \mathrm{O}_{3}\right.$-neutral-B2) was prepared by adding $3 \% \mathrm{w} / \mathrm{w}$ water to commercially available neutral activated alumina, briefly shaking, and allowing the mixture to equilibrate at room temperature in a sealed vial overnight. The effect of this altered alumina on the selectivity of the reduction was considerable yielding a product ratio 75:25 in favor of 1,2-reduction (entry 4). When the alumina was further rehydrated to Brockmann III (6 $\%$ water added) and IV (10\% water added) the selectivity dropped to 68:32 and 65:35 respectively (entries 5 and 6). Commercial suppliers typically offer neutral, basic, acidic versions of activated alumina. This terminology corresponds to the $\mathrm{pH}$ of a $5 \%$ aqueous suspensions of the aluminas which is approximately $9.5,7.5$, and 4.5 for basic, neutral and acidic aluminas respectively. ${ }^{15}$ Aluminas initially obtained by thermal activation of aluminum hydroxide are 'basic' and are subsequently neutralized and acidified by acid treatment under conditions which are proprietary with the degree of hydration remaining at Brockmann I for all 
three commercially available acidities. We evaluated basic and acidic activated aluminas at the Brockmann I, II, and III water content levels (entries 8-13). In all cases Brockmann II aluminas $(3 \% \mathrm{w} / \mathrm{w}$ water) gave a higher selectivity for 1,2-reduction than Brockmann I and III aluminas. Overall, acidic activated Brockmann II alumina $\left(\mathrm{Al}_{2} \mathrm{O}_{3}\right.$-acidic-B2, entry 12$)$ gave the most favorable 2 to 3 ratio of 79:21. Reaction workup in this study consisted of filtration, washing with EtOAc, and removal of solvent. Analysis of the crude filtrate residues by ${ }^{1} \mathrm{H}$ NMR showed primarily compounds 2 and 3 with no major impurities evident. No evidence of boron byproducts was observed via ${ }^{11} \mathrm{~B}$ NMR of the crude reaction mixture after filtration. Furthermore, the mass of alumina recovered after filtration and drying was higher than the initial mass suggesting presence of adsorbed boron species. Two other common amorphous solids, silica gel $\left(\mathrm{SiO}_{2}\right)$ and titania $\left(\mathrm{TiO}_{2}\right)$, also resulted in inferior 1,2-selectivity relative to the aluminas evaluated above.

Using the most effective alumina, $\mathrm{Al}_{2} \mathrm{O}_{3}$-acidic-B2, additional variables were optimized (Table 2). Increasing the amount of alumina from 1 to 3 grams per mmol of substrate corresponded to enhancement of selectivity to $84: 16$ with no further improvement observed at $4 \mathrm{~g} / \mathrm{mmol}$ (entries 1-4). The reaction rate increased substantially with the substrate consumed in 1 hour and a small drop in selectivity when the amount of $\mathrm{NaBH}_{4}$ was doubled to 2 equiv. (entry 5). All of the above reactions were performed as follows: a slurry of $\mathrm{NaBH}_{4}$ and alumina in ethyl acetate was stirred for 10 minutes before addition of the cyclohexenone. When the $\mathrm{NaBH}_{4} /$ alumina prestirring time was increased from 10 minutes to 4 hours the reaction rate slowed and selectivity fell to 59:41 (entry 6) while 8 hours of pre-stirring inhibited the reaction entirely (entry 7). These two experiments were interpreted to indicate that under these reaction conditions, in the absence of a substrate, $\mathrm{NaBH}_{4}$ is converted to species that are both less reactive and less 1,2selective toward the reduction of enones. Consequently, we altered the order of addition by combining the substrate and alumina in EtOAc for ten minutes prior to addition of $\mathrm{NaBH}_{4}$. This resulted in an increase of selectivity to 90:10 (entry 8). A sixty minute delay offered no additional benefit (entry 9). Two acidic aluminas purchased from different suppliers (see Supplementary Information) and rehydrated to Brockmann II offered comparable results to those of our original activated alumina (entries 10-11). Finally, replacement of $\mathrm{NaBH}_{4}$ with $\mathrm{NaCNBH}_{3}$ as the hydride source corresponded to a decrease in reaction rate and selectivity (entry 12) while $\mathrm{NaBH}(\mathrm{OAc})_{3}$ did not react with 2-cyclohexenone under these conditions resulting only in recovery of unreacted substrate (entry 13). 
Table 2. Optimization of Reduction in the presence of $\mathrm{Al}_{2} \mathrm{O}_{3}$-Acidic-B2. ${ }^{\mathrm{a}}$

\begin{tabular}{llllll} 
& & & & \\
\hline & & & & & \\
\hline
\end{tabular}

\footnotetext{
${ }^{\text {a. }}$ Reaction conditions: cyclohexenone ( $\left.1 \mathrm{mmol}\right)$, alumina, $\mathrm{NaBH}_{4}$, EtOAc $(10 \mathrm{~mL})$, r.t. Workup: filtration, washing with EtOAc, and removal of solvent; ${ }^{b} \mathrm{Al}_{2} \mathrm{O}_{3}$-acidic-B2 prepared from: aluminum oxide, activated, acidic, Brockmann I (Sigma-Aldrich \#199966); ${ }^{\text {c. }}$ Ratio determined via ${ }^{1} \mathrm{H}$ NMR after filtration; ${ }^{\text {d. }}$ No reaction observed.; ${ }^{\text {e. }} \mathrm{Al}_{2} \mathrm{O}_{3}$-acidic-B2 prepared from: aluminum oxide, activated, acidic, Brockmann I (Alfa Aesar \#11501); ${ }^{\text {f. }} \mathrm{Al}_{2} \mathrm{O}_{3}$-acidic-B2 prepared from: aluminum oxide, activated, acidic, gamma (Strem Chemicals \#93-1329);
}

The most favorable ratio of 1,2-reduction to 1,4-reduction of cyclohexenone was 90:10 (Table 2, entry 8). Although this procedure constitutes a practically simple and inexpensive approach to 1,2-selective reduction of unsaturated ketones, it is inferior to the Luche conditions in terms of selectivity in the case of 2-cyclohexenone (Table 1, entries 2).

The protocol was applied to seven additional $\alpha, \beta$-unsaturated ketones as summarized in Table 3 . We were pleased to observe that in all cases the selectivity was higher than that of our initial substrate with 4 of 8 enones reduced to their corresponding allylic alcohols with no 1,2-reduction observed (i.e., $>20: 1$ based on analysis of crude ${ }^{1} \mathrm{H}$ NMR spectra prior to purification). The reductions of 2-cyclohexenone, 3-octene-2-one, isophorone, and 3,5-dimethylcyclohexenone to their corresponding allylic alcohols 2, 5, 8 and 13 yielded mixtures with saturated alcohols in ratios of 90:10, 93:7, 97:3 and 95:5 respectively. In these cases the yields reported in Table 3 
correspond to mixtures of alcohols. We found that acetone was preferable to EtOAc for washing the alumina residue during filtration resulting in higher isolated yields which ranged from 64 to $93 \%$. Most of the reductions were complete in 1 or 2 hours with the exception of isophorone which failed to react completely after $48 \mathrm{~h}$. Alcohol 8 was obtained in just $64 \%$ in addition to some unreacted isophorone recovered. Allylic alcohols $\mathbf{9}$ and $\mathbf{1 0}$ were prepared in high diastereomeric ratios.

Table 3. Substrate Scope for $\mathrm{NaBH}_{4} / \mathrm{Al}_{2} \mathrm{O}_{3}$-acidic-B2 Reduction of Enones. ${ }^{\text {a }}$

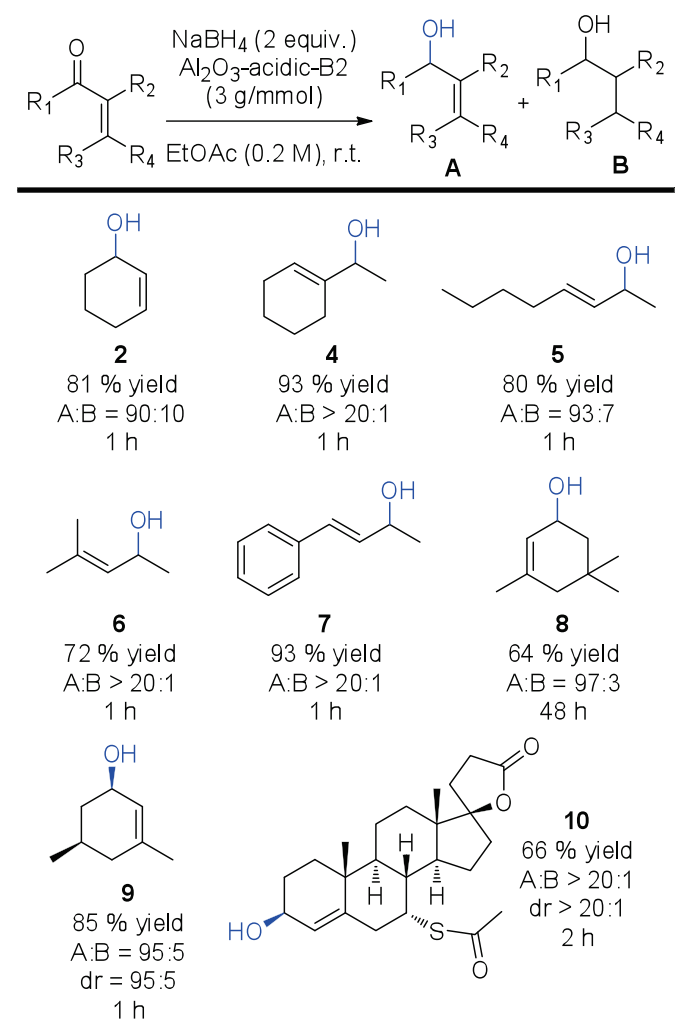

a. Reaction conditions: substrate ( $2 \mathrm{mmol}), \mathrm{Al}_{2} \mathrm{O}_{3}$-acidic-B2 $(6.0 \mathrm{~g})$, EtOAc $(10 \mathrm{~mL})$, r.t. $10 \mathrm{~min}$, then $\mathrm{NaBH}_{4}$ (4 mmol), r.t.; Workup via filtration with acetone wash; Ratios of $\mathrm{A}: \mathrm{B}$ and diastereomeric products were determined via ${ }^{1} \mathrm{H}$ NMR prior to chromatography (see Supplementary Information).

Regarding the mechanistic rationale for 1,2-selectivity in this reaction, based our observed optimal order of addition of the reagents (see Table 2), we believe that the likely hydride source in this process is $\mathrm{NaBH}_{4}$ rather than a hydroxyborohydride species analogous to the methoxyborohydrides of the Luche reduction. The $\mathrm{Al}^{3+}$ surface sites of $\mathrm{Al}_{2} \mathrm{O}_{3}$ act as a Lewis Acid to modulate the nature of electrophilicity of the substrate via coordination to the carbonyl moiety. The surface electronic environment of $\mathrm{Al}_{2} \mathrm{O}_{3}$, and consequently degree of Lewis Acidity, are strongly influenced by degree of hydration. ${ }^{16}$ The issue of why this particular level of hydration of acidic alumina is optimal for 1,2-selectivity in this reaction remains an open question. Indeed, delineating a mechanistic rationale for the observed selectivity under these 
reaction conditions presents a daunting challenge that is complicated not only by the heterogeneity of alumina but also by the low solubility of $\mathrm{NaBH}_{4}$ in ethyl acetate.

A few additional practical considerations are as follows. Spent alumina, which contains adsorbed boron byproducts, could not be re-used effectively. The selectivity in the reduction of 2-cyclohexanone decreased from 90:10 to 64:36 (2:3) upon reuse of spent alumina and the ratio continued to decrease with repeated use. The 1,2-reduction of 2-cyclopentenone, which is acknowledged to be especially prone to undergo 1,4-additions, ${ }^{9}$ does not occur under these conditions with only cyclopentanol formed. In the interest of familiarity to readers, we chose to employ the Brockmann numbering system throughout this initial study, however, there is no inherent reason for hydration corresponding to the arbitrary Brockmann I-V scale to be distinguished from any other intermediate values. In this reaction, Brockmann 1.5 and 2.5 aluminas (corresponding to 1.5 and $4.5 \% \mathrm{w} / \mathrm{w}$ water) did not offer any improvement in selectivity over Brockmann II. Nonetheless, as we continue our work in this area we have transitioned to a more systematic nomenclature that explicitly states the $\%$ water added, acidity level, and alumina polymorph where available; for example $\gamma-\mathrm{Al}_{2} \mathrm{O}_{3}$-acidic $+3 \% \mathrm{H}_{2} \mathrm{O}$.

From a practical perspective, given the ubiquity of activated aluminas in chemistry laboratories, it is surprising that their 'rehydration' has remained unexplored in the context of reactivity and selectivity in laboratory-scale organic synthesis. Interest is perhaps hampered by the proprietary and opaque nature of the industrial production of aluminas. In addition, adsorbed substrates do not interact with surface sites via consistent and well-defined transition states which would aid in the rationalization and prediction of selectivity.

Furthermore, a methodology that relies on a well-defined degree of hydration of alumina must address the fact that activated aluminas can adsorb water upon long term storage. This concern can be resolved by adoption of a standard dehydration protocol such as heating under vacuum at

$350-400{ }^{\circ} \mathrm{C},{ }^{49,50}$ prior to re-hydrating. Future work from our lab will address this issue in depth. Notably, the water content of alumina can be accurately measured via Karl Fischer titration. ${ }^{51}$

\section{Summary and conclusions}

In summary, we have demonstrated the selective reduction of $\alpha, \beta$-unsaturated ketones in a 1,2fashion by $\mathrm{NaBH}_{4}$ in EtOAc in the presence of activated acidic Brockmann II aluminas $\left(\mathrm{Al}_{2} \mathrm{O}_{3}\right.$ acidic-B2) prepared simply by adding $3 \%$ water to the corresponding commercially available Brockmann I alumina. Alumina is a potentially desirable replacement for $\mathrm{CeCl}_{3}$ and other homogeneous Lewis Acids which are more expensive and more difficult to separate from reaction products. In this case, eight substrates were reduced with selectivity for 1,2- over 1,4reduction ranging from 90:10 to $>20: 1$.

More generally, with our disclosure of this reaction we hope to draw attention to rehydration of activated alumina as a variable that may have a significant impact on reactivity and selectivity in synthetic chemistry. Activated aluminas are already present in many organic laboratories where they are used as chromatographic media and catalyst supports. They should also now be 
considered surfaces with acid/base properties that can be finely tuned by simple addition of water to impact reactivity and selectivity.

\section{Experimental section}

\section{General experimental details}

Infrared spectra were obtained on a Thermo Scientific Nicolet 380 FT-IR spectrometer as thin films on $\mathrm{ZnSe}$ disks and peaks are reported in $\mathrm{cm}^{-1} .{ }^{1} \mathrm{H}$ and ${ }^{13} \mathrm{C}$ NMR experiments were performed on a Bruker AVANCE $500 \mathrm{MHz}$ instrument and samples were obtained in $\mathrm{CDCl}_{3}$ (referenced to $7.26 \mathrm{ppm}$ for ${ }^{1} \mathrm{H}$ and $77.16 \mathrm{ppm}$ for ${ }^{13} \mathrm{C}$ ). Coupling constants $(\mathrm{J})$ are in $\mathrm{Hz}$. The multiplicities of the signals are described using the following abbreviations: $\mathrm{s}=$ singlet, $\mathrm{br} \mathrm{s}=$ broad singlet, $\mathrm{d}=$ doublet, $\mathrm{t}=$ triplet, $\mathrm{dd}=$ doublet of doublets, $\mathrm{dq}=$ doublet of quartets, $\mathrm{dsep}=$ doublet of septets; $\mathrm{tt}=$ triplet of triplets, $\mathrm{m}=$ multiplet, app $=$ apparent. MALDI-HRMS of compounds were recorded on a Q-TOF mass spectrometer. Reaction progress was monitored by thin-layer chromatography on silica gel plates (60-F254), observed under UV light and plates were stained using $p$-anisaldehyde. Column chromatography was performed using silica gel

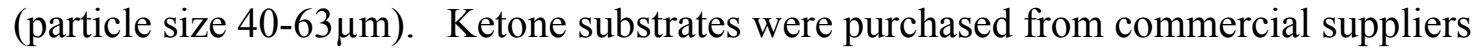
AKScientific, VWR, Aldrich, and used without further purification. Activated aluminas (Brockmann I) were purchased from Sigma-Aldrich, Alfa-Aesar, and Strem Chemicals and were rehydrated to Brockmann II, III, and IV levels as described below.

\section{Procedure for rehydration of activated aluminas to Brockmann II, III, \& IV grade.} Example: Activated acidic alumina Brockmann II (acidic- $\left.\mathbf{A l}_{\mathbf{2}} \mathbf{O}_{\mathbf{3}}-\mathbf{B} 2\right)$ ) To a $100 \mathrm{~mL}$ round bottomed flask was added activated acidic alumina Brockmann I (10.0 g) and deionized $\mathrm{H}_{2} \mathrm{O}$ $(0.30 \mathrm{~mL}, 3.0 \% \mathrm{w} / \mathrm{w})$. The flask was capped tightly and shaken until visible clumps were broken apart. The capped flask was allowed to sit at room temperature for a minimum of 12 hours before use. Analogous procedures were used to make Brockmann III aluminas using 0.60 $\mathrm{mL}(6.0 \% \mathrm{w} / \mathrm{w})$ of water and Brockmann IV aluminas using $1.0 \mathrm{~mL}(10 \% \mathrm{w} / \mathrm{w})$ of water. Note: Note: The choice of 12 hours of equilibration time was based on directions reported in a technical bulletin from Sigma Aldrich. ${ }^{15}$ Brockmann II-IV aluminas were generally prepared on multi-gram scale and stored in a sealed vessels without any notable change in reactivity observed over the course of several weeks of storage.

General procedure for 1,2 -reduction of $\boldsymbol{\alpha}, \boldsymbol{\beta}$-unsaturated ketones to allylic alcohols. To a reaction vial equipped with a stir bar were added: activated acidic alumina Brockmann II (acidic$\left.\mathrm{Al}_{2} \mathrm{O}_{3}-\mathrm{B} 2,6 \mathrm{~g}\right)$, EtOAc $(10 \mathrm{ml})$, and the $\alpha, \beta$-unsaturated ketone substrate $(2 \mathrm{mmol})$. The vial was capped and the mixture was stirred at room temperature for 10 minutes before $\mathrm{NaBH}_{4}(152 \mathrm{mg}$, $2.0 \mathrm{mmol}$ ) was added in one portion. The reaction vial was capped and the mixture was stirred at room temperature and monitored by TLC and/or ${ }^{1} \mathrm{H}$ NMR until complete disappearance of starting material was observed. The reaction mixture was filtered through filter paper (Whatman, 42 Ashless) and the solids washed with acetone (approximately $3 \times 20 \mathrm{~mL}$ ). The filtrate was concentrated in vacuo and the residue purified via flash column chromatography on silica gel (EtOAc/hexanes with gradient elution).

\section{Characterization of allylic alcohols 2, 4-10}


2-cyclohexenol (2): The general procedure was used with 2-cyclohexen-1-one (193.6 $\mu \mathrm{L}, 2.0$ $\mathrm{mmol}$ ). After 1 hour the reaction mixture was filtered and purified as described above to yield a mixture of 2-cyclohexenol and cyclohexanol (90:10 ratio, $159 \mathrm{mg}, 81 \%$ yield corresponding to both alcohols); pale yellow oil; $\mathrm{R}_{\mathrm{f}}=0.36$ (hexanes/EtOAc 70:30 v/v); ${ }^{1} \mathrm{H}$ NMR $(500 \mathrm{MHz}$, $\left.\mathrm{CDCl}_{3}\right) \delta 5.81-5.77(\mathrm{~m}, 1 \mathrm{H}), 5.73-5.69(\mathrm{~m}, 1 \mathrm{H}), 4.18-4.13(\mathrm{~m}, 1 \mathrm{H}), 2.09-1.48(\mathrm{~m}, 7 \mathrm{H}) ;{ }^{13} \mathrm{C}$ NMR $\left(125 \mathrm{MHz}, \mathrm{CDCl}_{3}\right) \delta 130.5,130.1,65.6,32.1,25.2,19.1$. This NMR data is consistent with an authentic sample from Sigma Aldrich. cyclohexanol: ${ }^{1} \mathrm{H}$ NMR $\delta 3.60-3.53(\mathrm{~m}, 1 \mathrm{H}$, $\mathrm{CHOH}$ ); this resonance was consistent with an authentic sample and was used to determine product ratio.

1-(cyclohexen-1-yl) ethanol (4): The general procedure was used with 2-cyclohexen-1-one $(258.7 \mu \mathrm{L}, 2.0 \mathrm{mmol})$. After 1 hour the reaction mixture was filtered and purified as described above to yield 1-(cyclohexen-1-yl) ethanol (234 mg, 93\% yield); colorless oil; $\mathrm{R}_{\mathrm{f}}=0.51$ (hexanes/EtOAc 70:30 v/v); ${ }^{1} \mathrm{H}$ NMR $\left(500 \mathrm{MHz}, \mathrm{CDCl}_{3}\right) \delta 5.65-5.62(\mathrm{~m}, 1 \mathrm{H}), 4.13(\mathrm{q}, J=6.5$ $\mathrm{Hz}, 1 \mathrm{H}), 2.03-1.92(\mathrm{~m}, 4 \mathrm{H}), 1.77(\mathrm{~s}, 1 \mathrm{H}), 1.66-1.50(\mathrm{~m}, 4 \mathrm{H}), 1.22(\mathrm{~d}, J=6.5 \mathrm{~Hz}, 3 \mathrm{H}) .{ }^{13} \mathrm{C}$ NMR $\left(125 \mathrm{MHz}, \mathrm{CDCl}_{3}\right) \delta 141.4,121.5,72.2,25.0,24.8,22.8,22.7,21.6$. This NMR data is consistent with previously reported values. ${ }^{52}$

Oct-3-en-2-ol (5): The general procedure was used with 3-octen-2-one (296.9 $\mu \mathrm{L}, 2.0 \mathrm{mmol})$. After 1 hour the reaction mixture was filtered and purified as described above to yield a mixture of oct-3-en-2-ol and 2-octanol (93:7 ratio, $205 \mathrm{mg}, 80 \%$ yield corresponding to both alcohols); colorless oil; $\mathrm{R}_{\mathrm{f}}=0.66\left(\right.$ Hexanes/EtOAc 70:30 v/v); ${ }^{1} \mathrm{H}$ NMR $\left(500 \mathrm{MHz}, \mathrm{CDCl}_{3}\right) \delta 5.63(\mathrm{dt}, J=$ 15.4, $6.7 \mathrm{~Hz}, 1 \mathrm{H}), 5.54-5.48(\mathrm{~m}, 1 \mathrm{H}), 4.28-4.22(\mathrm{~m}, 1 \mathrm{H}), 2.02(\mathrm{q}, J=7.4 \mathrm{~Hz}, 2 \mathrm{H}), 1.47$ (br s, $1 \mathrm{H}), 1.37-1.28(\mathrm{~m}, 4 \mathrm{H}), 1.21(\mathrm{~d}, J=6.3 \mathrm{~Hz}, 3 \mathrm{H}), 0.93-0.86(\mathrm{~m}, 3 \mathrm{H}) ;{ }^{13} \mathrm{C} \mathrm{NMR}(125 \mathrm{MHz}$, $\left.\mathrm{CDCl}_{3}\right) \delta 134.3,131.3,69.2,31.9,31.5,23.6,22.3,14.0$. This NMR data is consistent with previously reported values. ${ }^{53}$ 2-octanol: ${ }^{1} \mathrm{H}$ NMR $\delta 3.82-3.75(\mathrm{~m}, 1 \mathrm{H}, \mathrm{C} \underline{\mathrm{HOH}})$; this resonance was consistent with an authentic sample and was used to determine product ratio.

4-methylpent-3-en-ol (6): The general procedure was used with mesityl oxide ( $228.79 \mu \mathrm{L}, 2.0$ $\mathrm{mmol})$. After 1 hour the reaction mixture was filtered and purified as described above to yield 4methylpent-3-en-ol (144 mg, 72\% yield); colorless liquid; $\mathrm{R}_{\mathrm{f}}=0.42$ (Hexanes/EtOAc 70:30 $\mathrm{v} / \mathrm{v}) ;{ }^{1} \mathrm{H}$ NMR $\left(500 \mathrm{MHz}, \mathrm{CDCl}_{3}\right) \delta 5.21$ (app dsep, $\left.J=8.4,1.4 \mathrm{~Hz}, 1 \mathrm{H}\right), 4.56$ (dq, $J=8.5,6.2$ $\mathrm{Hz}, 1 \mathrm{H}), 1.71(\mathrm{~d}, J=1.4 \mathrm{~Hz}, 3 \mathrm{H}), 1.69(\mathrm{~d}, J=1.4 \mathrm{~Hz}, 3 \mathrm{H}), 1.23(\mathrm{~d}, J=6.2 \mathrm{~Hz}, 3 \mathrm{H}){ }^{13} \mathrm{C}$ NMR $\left(125 \mathrm{MHz}, \mathrm{CDCl}_{3}\right) \delta 134.4,129.5,65.0,29.8,25.8,23.8,18.2$. This NMR data is consistent with previously reported values. ${ }^{54}$

4-Phenyl-3-buten-2-ol (7): The general procedure was used with 4-phenyl-3-buten-2-one (292 $\mathrm{mg}, 2.0 \mathrm{mmol})$. After 48 hours, the reaction mixture was filtered and purified as described above to yield 4-Phenyl-3-buten-2-ol (276 mg, 93\% yield); colorless oil; $\mathrm{R}_{\mathrm{f}}=0.59$ (Hexanes/EtOAc $70: 30 \mathrm{v} / \mathrm{v}) ;{ }^{1} \mathrm{H}$ NMR $\left(500 \mathrm{MHz}, \mathrm{CDCl}_{3}\right) \delta 7.38(\mathrm{~d}, J=7.1 \mathrm{~Hz}, 2 \mathrm{H}), 7.32(\mathrm{t}, J=7.5 \mathrm{~Hz}, 2 \mathrm{H}), 7.24$ $(\mathrm{t}, J=7.3 \mathrm{~Hz}, 1 \mathrm{H}), 6.57(\mathrm{~d}, J=15.9 \mathrm{~Hz}, 1 \mathrm{H}), 6.27(\mathrm{dd}, J=15.9,6.4 \mathrm{~Hz}, 1 \mathrm{H}), 4.50($ app pd, $J=$ $6.3,1.2 \mathrm{~Hz}, 1 \mathrm{H}), 1.56(\mathrm{br} \mathrm{s}, 1 \mathrm{H}), 1.38(\mathrm{~d}, J=6.4 \mathrm{~Hz}, 3 \mathrm{H}) .{ }^{13} \mathrm{C} \mathrm{NMR}\left(125 \mathrm{MHz}, \mathrm{CDCl}_{3}\right) \delta 136.9$, $133.7,129.6,128.7,127.8,126.6,69.1,23.6$. This NMR data is consistent with previously reported values. ${ }^{54}$ 
3,5,5-trimethylcyclohex-2-en-1-ol (8): The general procedure was used with isophorone (299 $\mu \mathrm{L}, 2.0 \mathrm{mmol}$ ). After 48 hours, the reaction mixture was filtered and purified as described above to yield mixture of 3,5,5-trimethylcyclohex-2-en-1-ol and cis-3,3,5-trimethylcyclohexanol (97:3 ratio; $179 \mathrm{mg}, 64 \%$ yield corresponding to both alcohols); colorless oil; $\mathrm{R}_{\mathrm{f}}=0.45$ (Hexanes/EtOAc 70:30 v/v); ${ }^{1} \mathrm{H}$ NMR $\left(500 \mathrm{MHz}, \mathrm{CDCl}_{3}\right) \delta 5.41(\mathrm{dq}, J=2.5,1.2 \mathrm{~Hz}, 1 \mathrm{H}), 4.24$ $-4.18(\mathrm{~m}, 1 \mathrm{H}), 1.87-1.79(\mathrm{~m}, 1 \mathrm{H}), 1.78-1.71(\mathrm{~m}, 1 \mathrm{H}), 1.66(\mathrm{~s}, 3 \mathrm{H}), 1.62-1.56(\mathrm{~m}, 1 \mathrm{H}), 1.21$ $(\mathrm{dd}, J=12.4,9.0 \mathrm{~Hz}, 1 \mathrm{H}), 0.98(\mathrm{~s}, 3 \mathrm{H}), 0.87(\mathrm{~s}, 3 \mathrm{H}) ;{ }^{13} \mathrm{C} \mathrm{NMR}\left(125 \mathrm{MHz}, \mathrm{CDCl}_{3}\right) \delta 136.1$, $123.8,67.0,45.4,44.3,31.3,31.2,26.4,23.6$. This NMR data is consistent with previously reported values. ${ }^{52}$ cis-3,3,5-trimethylcyclohexanol: ${ }^{1} \mathrm{H}$ NMR $\delta 3.78-3.71(\mathrm{~m}, 1 \mathrm{H}, \mathrm{CHOH})$; this resonance was consistent previously reported data and was used to determine product ratio. ${ }^{55}$

cis-3,5-dimethylcyclohex-2-enol (9): The general procedure was used with 3,5dimethylcyclohexenone $(248 \mathrm{mg}, 2.0 \mathrm{mmol})$. After 1 hour, the reaction mixture was filtered and purified as described above to yield a mixture of cis-3,5-dimethylcyclohex-2-enol and three minor byproducts: trans-3,5-dimethylcyclohex-2-enol (9A), 3,5-cis-dimethyl-1-cis-cyclohexanol (9B), and 3,5-cis-dimethyl-1-trans-cyclohexanol (9C). (9: 9A : 9B : 9C ratio of 100:5:4:1 see below; $214 \mathrm{mg}, 85 \%$ yield corresponding to all four alcohols); colorless oil; $\mathrm{R}_{\mathrm{f}}=0.56$ (Hexanes/EtOAc 70:30 v/v); cis-3,5-dimethylcyclohex-2-enol (11): ${ }^{1} \mathrm{H}$ NMR $(500 \mathrm{MHz}$, $\left.\mathrm{CDCl}_{3}\right) \delta 5.38(\mathrm{dq}, J=2.3,1.2 \mathrm{~Hz}, 1 \mathrm{H}), 4.30-4.23(\mathrm{~m}, 1 \mathrm{H}), 2.04-1.99(\mathrm{~m}, 1 \mathrm{H}), 1.90(\mathrm{dd}, J=$ $17.2,4.7 \mathrm{~Hz}, 1 \mathrm{H}), 1.77-1.68(\mathrm{~m}, 1 \mathrm{H}), 1.67(\mathrm{~d}, J=1.3 \mathrm{~Hz}, 3 \mathrm{H}), 1.64-1.56(\mathrm{~m}, 1 \mathrm{H}), 1.08-0.99$ $(\mathrm{m}, 1 \mathrm{H}), 0.98(\mathrm{~d}, J=6.6 \mathrm{~Hz}, 3 \mathrm{H}) ;{ }^{13} \mathrm{C} \mathrm{NMR}\left(125 \mathrm{MHz}, \mathrm{CDCl}_{3}\right.$ ) $) \delta 137.0,125.6,68.7,41.6,39.0$, 28.4, 23.3, 22.0. trans-3,5-dimethylcyclohex-2-enol (9A): ${ }^{1} \mathrm{H}$ NMR $\delta 4.18$ (br s, $1 \mathrm{H}, \mathrm{C} \underline{\mathrm{HOH}}$ ); 3,5-cis-dimethyl-1-cis-cyclohexanol (9B): ${ }^{1} \mathrm{H}$ NMR $\delta 3.60$ (tt, $J=11.1,4.3 \mathrm{~Hz}, 1 \mathrm{H}, \mathrm{C} \underline{\mathrm{HOH}}$ ); 3,5-cis-dimethyl-1-trans-cyclohexanol (9C): ${ }^{1} \mathrm{H}$ NMR $\delta 4.13-4.10$ (m, 1H, $\mathrm{CHOH}$ ); The ratio of unsaturated to saturated alcohols $=95: 5$ and the ratio of cis:trans allylic alcohol diastereomers $(\mathbf{9 : 9 A})=95: 5$. (See Supporting Information) The above NMR resonances are consistent with previously reported data. ${ }^{56}$

Compound 10: The general procedure was used with spironolactone (209 $\mathrm{mg}, 0.5 \mathrm{mmol}$ ), acidic- $\mathrm{Al}_{2} \mathrm{O}_{3}-\mathrm{B} 2(1.5 \mathrm{~g})$, EtOAc $(5 \mathrm{ml})$ and $\mathrm{NaBH}_{4}(38 \mathrm{mg}, 1.0 \mathrm{mmol})$. After 2 hours the reaction mixture was filtered and purified as described above to yield compound $10(137 \mathrm{mg}, 66$ $\%$ yield); colorless oil; $\mathrm{R}_{\mathrm{f}}=0.7$ (Hexanes/EtOAc 70:30 v/v); ${ }^{1} \mathrm{H}$ NMR $\left(500 \mathrm{MHz}, \mathrm{CDCl}_{3}\right) \delta 5.30$ $-5.28(\mathrm{~m}, 1 \mathrm{H}), 4.20$ (dddd, $J=10.0,6.0,2.1,2.1 \mathrm{~Hz}, 1 \mathrm{H}), 3.90($ app q, $J=3.7 \mathrm{~Hz}, 1 \mathrm{H}), 2.67$ (dddd, $J=14.3,4.0,2.0 \mathrm{~Hz}, 1 \mathrm{H}), 2.57-2.41(\mathrm{~m}, 2 \mathrm{H}), 2.39-2.30(\mathrm{~m}, 1 \mathrm{H}), 2.32(\mathrm{~s}, 3 \mathrm{H}), 2.23-$ $2.16(\mathrm{~m}, 1 \mathrm{H}), 2.09(\mathrm{dd}, J=14.3,2.7 \mathrm{~Hz}, 1 \mathrm{H}), 1.99-1.86(\mathrm{~m}, 3 \mathrm{H}), 1.82-1.69(\mathrm{~m}, 2 \mathrm{H}), 1.64(\mathrm{br}$ $\mathrm{s}, 1 \mathrm{H}), 1.61-1.31(\mathrm{~m}, 8 \mathrm{H}), 1.28-1.20(\mathrm{~m}, 2 \mathrm{H}), 1.08(\mathrm{~s}, 3 \mathrm{H}), 1.03-0.94(\mathrm{~m}, 1 \mathrm{H}), 0.94(\mathrm{~s}, 3 \mathrm{H})$, $0.80(\mathrm{td}, J=11.8,4.5 \mathrm{~Hz}, 1 \mathrm{H}) ;{ }^{13} \mathrm{C} \mathrm{NMR}\left(125 \mathrm{MHz}, \mathrm{CDCl}_{3}\right) \delta 194.9,176.8,142.1,127.9,95.9$, 67.6, 50.0, 46.2, 46.1, 45.6, 39.4, 39.3, 37.5, 35.4, 35.3, 31.4, 31.4, 31.3, 29.4, 29.2, 22.5, 20.5, 19.2, 14.7; IR $\left(\mathrm{cm}^{-1}\right): 3435,2938,1767,1683,1177$; HRMS calculated for $\mathrm{C}_{24} \mathrm{H}_{34} \mathrm{O}_{4} \mathrm{~S}(\mathrm{M}+\mathrm{H})^{+}$ 419.22506; found 419.2249. Stereochemistry at C-3 ( $\beta$-epimer) was inferred via comparison of ${ }^{1} \mathrm{H}$ NMR resonance $\mathrm{C}_{3}-\mathrm{H}$ to a similar compound. ${ }^{57}$ (See Supporting Information)

\section{Acknowledgements}


This work was made possible by support from the National Science Foundation (Grant \# 1301506). L.N. received research support from an IDeA award from the NIGMS (Grant \#P20GM103408). We thank Dr. Alex Blumenfeld and Dr. Lee Deobald for NMR and HRMS analyses respectively.

\section{Corresponding Author}

*jmagolan@uidaho.edu

\section{Author Contributions}

These authors contributed equally.

Notes: The authors declare no competing financial interests.

\section{References and notes}

1. Hudson, K. L.; Misra, C.; Perrotta, A. J.; Wefers, K.; Williams, F. S., In Ullmann's Encyclopedia of Industrial Chemistry, Wiley-VCH: Hoboken, NJ, 2003; pp 339-378.

2. Misra, C., Industrial Alumina Chemicals. American Chemical Society: Washington, DC, 1986.

3. Busca, G. Catal. Today 2014, 226,

4. Levin, I.; Brandon, D. J. Am. Ceram. Soc. 1998, 81,

5. Knözinger, H.; Ratnasamy, P. Cat. Rev. - Sci. Eng. 1978, 17,

6. Coster, D.; Blumenfeld, A.; Fripiat, J. J. Phys. Chem. 1994, 98 ,

7. Kabalka, G. W.; Pagni, R. M. Tetrahedron 1997, 53,

8. Varma, R. S. Green Chem. 1999, 1,

9. Posner, G. H. Angew. Chem. Int. Ed. 1978, 17,

10. Posner, G. H.; Rogers, D. J. Am. Chem. Soc. 1977, 99,

11. Ballini, R.; Clemente, R. R.; Palmieri, A.; Petrini, M. Adv. Synth. Catal. 2006, 348,

12. Bartoli, G.; Bartolacci, M.; Giuliani, A.; Marcantoni, E.; Massaccesi, M.; Torregiani, E. J. Org. Chem 2005, 70,

13. Ballini, R.; Bosica, G.; Fiorini, D.; Palmieri, A. Green Chem. 2005, 7,

14. Brockmann, H.; Schodder, H. Ber. 1941, 74,

15. Mineral Adsorbents, Filter Agents and Drying Agents (Aldrich Technical Information Bulletin AL143); Aldrich Chemical Co., Milwaukee, WI.

16. Wischert, R.; Laurent, P.; Copéret, C.; Delbecq, F. o.; Sautet, P. J. Am. Chem. Soc. 2012, 134 ,

17. Sartori, G.; Ballini, R.; Bigi, F.; Bosica, G.; Maggi, R.; Righi, P. Chem. Rev. 2004, 104,

18. Maggi, R.; Ballini, R.; Sartori, G.; Sartorio, R. Tetrahedron Lett. 2004, 45,

19. Rosini, G.; Galarini, R.; Marotta, E.; Righi, P. J. Org. Chem 1990, 55,

20. Koreeda, M.; Ricca, D. J.; Luengo, J. I. J. Org. Chem 1988, 53,

21. Hudrlik, P. F.; Hudrlik, A. M.; Kulkarni, A. K. Tetrahedron Lett. 1985, 26, 
22. van Vliet, M. C.; Mandelli, D.; Arends, I. W.; Schuchardt, U.; Sheldon, R. A. Green Chem. 2001, 3,

23. Rinaldi, R.; Schuchardt, U. J. Catal. 2004, 227,

24. Rinaldi, R.; Sepulveda, J.; Schuchardt, U. Adv. Synth. Catal. 2004, 346,

25. Rinaldi, R.; Schuchardt, U. J. Catal. 2005, 236,

26. Heravi, M. M.; Ajami, D.; Shoar, R. H.; Sarmad, N.; Faridbod, F. Phosphorus Sulfur Silicon Relat. Elem. 2004, 179,

27. Heravi, M. M.; Ajami, D.; Ghassemzadeh, M. Synth. Commun. 1999, 29,

28. Varma, R. S.; Saini, R. K. Tetrahedron Lett. 1998, 39,

29. Alavi Nikje, M. M.; Bigdeli, M. A. Phosphorus Sulfur Silicon Relat. Elem. 2004, 179,

30. Bigdeli, M. A.; Nikje, M. M. A.; Heravi, M. M. Phosphorus Sulfur Silicon Relat. Elem. 2002, 177,

31. Greenhalgh, R. P. Synlett 1992,

32. Hirano, M.; Oose, M.; Morimoto, T. Chem. Lett. 1991,

33. Ganguly, N. C.; De, P.; Sukai, A. K.; De, S. Synth. Commun. 2002, 32 ,

34. Caddick, S.; Murtagh, L.; Weaving, R. Tetrahedron 2000, 56,

35. Weires, N. A.; Boster, J.; Magolan, J. Eur. J. Org. Chem. 2012, 2012,

36. Karki, M.; Araujo, H. C.; Magolan, J. Synlett 2013, 24,

37. Luche, J. L. J. Am. Chem. Soc. 1978, 100,

38. Gemal, A. L.; Luche, J. L. J. Am. Chem. Soc. 1981, 103,

39. Brown, H. C.; Hess, H. M. J. Org. Chem. 1969, 34,

40. Wilson, K.; Seidner, R.; Masamune, S. J. Chem. Soc. D., Chem. Commun. 1970,

41. Krishnamurthy, S.; Brown, H. C. J. Org. Chem. 1975, 40,

42. Krishnamurthy, S.; Brown, H. C. J. Org. Chem. 1977, 42,

43. Cha, J. S.; Kwon, O. O.; Kwon, S. Y. Org Prep Proced Int 1996, 28,

44. Fujii, H.; Oshima, K.; Utimoto, K. Chem. Lett. 1991,

45. Forkel, N. V.; Henderson, D. A.; Fuchter, M. J. Green Chem. 2012, 14,

46. Nardi, M.; Sindona, G.; Costanzo, P.; Oliverio, M.; Procopio, A. Tetrahedron 2015, 71,

47. Moghaddam, F. M.; Sharifi, A. Synth. Commun. 1995, 25,

48. Kamitori, Y.; Hojo, M.; Masuda, R.; Yoshida, T. Tetrahedron Lett. 1985, 26,

49. Gaetano, K.; Pagni, R. M.; Kabalka, G. W.; Bridwell, P.; Walsh, E.; True, J.;

Underwood, M. J. Org. Chem. 1985, 50,

50. Posner, G. H.; Rogers, D. Z.; Kinzig, C. M.; Gurria, G. M. Tetrahedron Lett. 1975, 16,

51. Bryant, W.; Mitchell Jr, J.; Smith, D. M.; Ashby, E. J. Am. Chem. Soc. 1941, 63,

52. Cho, B. T.; Kang, S. K.; Kim, M. S.; Ryu, S. R.; An, D. K. Tetrahedron 2006, 62,

53. Lu, Z.; Ma, S. J. Org. Chem. 2006, 71,

54. Hall, J. F.; Bourne, R. A.; Han, X.; Earley, J. H.; Poliakoff, M.; George, M. W. Green Chem. 2013, 15,

55. Alonso, F.; Riente, P.; Yus, M. Tetrahedron 2008, 64,

56. Chen, J.-X.; Daeuble, J. F.; Brestensky, D. M.; Stryker, J. M. Tetrahedron 2000, 56,

57. Parr, M. K.; Zapp, J.; Becker, M.; Opfermann, G.; Bartz, U.; Schänzer, W. Steroids 2007, 72 , 